\title{
Commentary \\ Do breast implants after a mastectomy affect subsequent prognosis and survival?
}

\author{
Louise A Brinton \\ Division of Cancer Epidemiology and Genetics, National Cancer Institute, Bethesda, MD, USA \\ Corresponding author: Louise A Brinton, Brinton@nih.gov \\ Published: 9 February 2005 \\ Breast Cancer Res 2005, 7:61-63 (DOI 10.1186/bcr1003) \\ (C) 2005 BioMed Central Ltd \\ See related Research article by Le et al., http://breast-cancer-research.com/content/7/2/R184
}

\begin{abstract}
In a large study, published in this issue of Breast Cancer Research, Le and colleagues report that women receiving implants after mastectomies for early-stage breast cancer experience lower breast cancer mortality than women not receiving implants. Assessment of survival patterns among women receiving reconstructive implants is complex given unique patient characteristics, disease attributes, and treatment patterns. The interpretation of reduced mortality from breast cancer must be assessed in light of significantly reduced risks of death from most other causes. In contrast, patients receiving post-mastectomy implants had elevated rates of suicide, consistent with findings among women with cosmetic implants. Additional well-designed investigations are needed to clarify survival patterns among women receiving reconstructive implants.
\end{abstract}

\section{Introduction}

In this issue of Breast Cancer Research, Le and colleagues [1] report on an important issue, namely the survival experience of women receiving breast implants after mastectomies for early-stage breast cancer. Although the long-term health effects associated with cosmetic breast implants have been extensively debated, less attention has focused on reconstructive implants [2]. Clarification of effects is important, given the impaired survival of women with breast cancer and the fact that increasing numbers of women are choosing reconstruction to improve their quality of life after mastectomy.

\section{Complexities of interpreting data}

In an investigation that had several strengths, including a relatively large size, a focus on a nationally representative group of patients, long-term follow-up and available information on types of implants, it was found that one-fifth of women diagnosed with early-stage breast cancers received post-mastectomy implants. Although these women were found to have a significantly lower all-cause mortality and lower mortality from breast cancer, the interpretation of these relationships is complex, necessitating an evaluation of both the characteristics of the women who decide to seek reconstructive surgery and the effects of medical factors associated with their diagnoses. The authors discuss limitations of their data, but there is in fact substantial evidence that several of these might have seriously hindered the true interpretation of the effects of reconstructive implants.

\section{Patient characteristics}

It is notable that only a limited amount of information was available on patient characteristics associated with the seeking of implants. It was clear from information presented that women who obtained implants had several unique attributes. Notably, they tended to be younger and non-Hispanic whites, which is consistent with observations made elsewhere about unique attributes of women obtaining reconstructive surgery [3-5]. Although it was possible in analyses to account for both age and race, of concern was the inability of the study to adjust completely for two major lifestyle predictors of breast cancer prognosis, namely socioeconomic status and body size. The investigators found no evidence that adjustment for census-level socioeconomic indicators in the San Francisco Bay area affected risks, but this indicator only crudely measures socioeconomic class. Evidence that higher family income is a significant predictor of whether a woman decides to seek reconstructive surgery [4] emphasizes the need for careful control for associated parameters. Similarly, an inability to account for obesity, also associated with poor survival from breast cancer [6], limits interpretation of the results. Although this factor has not been extensively examined in relation to reconstructive surgery, it is well recognized that women who seek cosmetic implants tend to be thin [7-9]. Inabilities to adjust for both higher socioeconomic status and lower body mass could have resulted in attenuations in both overall and breast cancer mortality among women with implants.

\section{Differences in disease attributes}

Attention must also focus upon effects of differences in disease attributes between implanted and non-implanted 
women. Notably, the proportion of in situ breast cancers was twice as high in women with breast implants, and women with implants were less likely to be diagnosed with more than one primary tumor. Attempts to adjust for stage of disease might not have adequately accounted for important disease differences, because it is well recognized that the decision regarding whether to seek implants is a complex one that is often closely associated with close access to a physician and his or her opinion as to the advisability of the procedure $[3,10,11]$. Thus, if women with only the most seemingly favorable prognoses had been advised to seek reconstruction, the results could have been significantly biased toward the favorable prognostic findings reported.

\section{Treatment effects}

Given that another key prognostic factor is therapy, consideration must also be given to whether there were differential treatment effects between implanted and nonimplanted women. Only limited treatment information was available. Findings elsewhere that patients seeking reconstructive surgery are more likely to be treated at National Cancer Institute-designated cancer centers [4] suggests that quality-of-care issues might have important contributory effects. This might particularly affect in situ cancers, because the approach to treatment for these tumors (especially ductal carcinomas) has been shown to vary substantially across clinical settings [12]. Results from Le and colleagues' data indicating that reconstructive patients were less likely to receive radiation therapy also support the notion of differential treatment effects. This finding is not surprising, given that immediate breast reconstruction can interfere with post-mastectomy radiation therapy and that post-mastectomy radiation can adversely affect the aesthetic outcome of an immediate breast reconstruction [13]. Given the myriad of other subtle differences that can affect the treatment course for patients, it might be impossible to completely control for treatment effects within the context of an observational study, as has been reported by Le and colleagues [1]. Thus, a more desirable approach to assessing the longterm effects of reconstructive surgery might be within the context of a clinical trial, where treatment effects can be more fully taken into account.

\section{Other methodologic limitations}

Finally, the results of the study must be interpreted in the light of some other methodologic limitations, including losses due to questionnaire non-response and lack of follow-up information, necessitating the evaluation of mortality for only three-quarters of the total series of women identified for study. In addition, it was necessary for deceased study subjects that information on implant status be obtained from the next-of-kin. Although the investigators used different methods of accruing person- information, whether selection biases could have affected the results remains of concern.

\section{Noncancer causes of death}

That the limitations in the available data might have seriously affected the results of the study is emphasized by findings that women with implants were at a lowered risk of most causes of death. Of note was the significantly reduced risk of death for cardiovascular events. The mortality findings are for the most part consistent with those observed in patients with cosmetic implants, when comparisons are made with the general population [14-16]. However, when the mortality experience of patients with cosmetic implants has been compared with that of patients seeking other types of plastic surgery, few differences have been observed, suggesting that individuals seeking plastic surgery are consistently healthier than other women [14]. Similarly, the decrease in nearly all causes of death in Le and colleagues' study suggests that patients receiving reconstructive implants are not comparable with the general population, requiring that extra caution be exercised in interpreting results. In view of this, it seems premature that the paper discusses biologic mechanisms that could lead to a survival advantage for breast cancer in women with reconstructive implants.

\section{Suicide excess}

In contrast to the reduced risk of most causes of death was an excess risk of suicide among women receiving reconstructive surgery. Although several studies have now documented a similar excess risk of suicide among women receiving cosmetic implants $[14,15,17]$, this is the first report of the relationship also extending to women receiving reconstructive implants. It is unclear why women with cosmetic implants have higher rates of suicide, although predisposing personality characteristics have been suggested as a possible contributing factor, since women seeking cosmetic implants have been shown to have varying degrees of low self-esteem, anxiety and depression, including severe depression or suicidal thoughts [18-20]. However, whether the increased suicide risk is due to predisposing characteristics or to post-implant dissatisfaction cannot at the moment be deciphered. Short-term complications associated with breast implants are well recognized, and may be enhanced among women receiving implants for reconstructive purposes [21]. Some support for postimplantation effects derives from studies in Denmark which show that women seeking implants have similar frequencies of prior depression than other patients [9], but higher rates of post-implantation use of psychotropic drugs [22]. Nonetheless, it would seem advisable that women seeking implant surgery, regardless of whether for cosmetic or reconstructive purposes, be appropriately evaluated and counseled to ensure that they are properly suited for the procedure. 


\section{Conclusion}

Although the results of this study shed some light on the mortality experience of women seeking reconstructive surgery after mastectomies, inabilities to account for a variety of factors that could lead to a survival advantage in these women necessitate cautious interpretation of the results. Before concluding that breast implants have beneficial effects on survival, additional studies are needed that will permit a variety of lifestyle and disease parameters to be fully taken into account. To shed further light on this issue, an investigation of effects within the context of breast cancer treatment trials seems warranted. Alternatively, further insights might be derived from comparing the mortality experience of women who opt for reconstructive implants (either silicone or saline) versus autologous tissue reconstruction. Given increased recognition of the importance of reconstructive surgery in improving the quality of life after a diagnosis of breast cancer, it is hoped that further well-designed investigations of survival patterns among women with reconstructive implants will be undertaken.

\section{Competing interests}

The author(s) declare that they have no competing interests.

\section{References}

1. Le GM, O'Malley CD, Glaser SL, Lynch CF, Stanford JL, Keegan THM, West DW: Breast implants following mastectomy in women with early-stage breast cancer: prevalence and impact on survival. Breast Cancer Res 2005, 7:R184-R193.

2. Committee on the Safety of Silicone Breast Implants, Division of Health Promotion and Disease Prevention, Institute of Medicine: Safety of Silicone Breast Implants. Washington, DC: National Academy Press; 2000.

3. Alderman AK, McMahon L Jr, Wilkins EG: The national utilization of immediate and early delayed breast reconstruction and the effect of sociodemographic factors. Plast Reconstr Surg 2003, 111:695-703.

4. Morrow M, Scott SK, Menck HR, Mustoe TA, Winchester DP: Factors influencing the use of breast reconstruction postmastectomy: a National Cancer Database study. J Am Coll Surg 2001, 192:1-8.

5. Tseng JF, Kronowitz SJ, Sun CC, Perry AC, Hunt KK, Babiera GV, Newman LA, Singletary SE, Mirza NQ, Ames FC, et al.: The effect of ethnicity on immediate reconstruction rates after mastectomy for breast cancer. Cancer 2004, 101:1514-1523.

6. Dignam JJ, Mamounas EP: Obesity and breast cancer prognosis: an expanding body of evidence. Ann Oncol 2004, 15:850-851.

7. Brinton LA, Brown SL, Colton T, Burich MC, Lubin J: Characteristics of a population of women with breast implants compared with women seeking other types of plastic surgery. Plast Reconstr Surg 2000, 105:919-927.

8. Fryzek JP, Weiderpass E, Signorello LB, Hakelius L, Lipworth L, Blot WJ, McLaughlin JK, Nyren O: Characteristics of women with cosmetic breast augmentation surgery compared with breast reduction surgery patients and women in the general population of Sweden. Ann Plast Surg 2000, 45:349-356.

9. Kjoller k, Holmich LR, Fryzek JP, Jacobsen PH, Friis S, McLaughlin JK, Lipworth L, Henriksen TF, Jorgensen S, Bittman S, et al.: Characteristics of women with cosmetic breast implants compared with women with other types of cosmetic surgery and population-based controls in Denmark. Ann Plast Surg 2003, 50:6-12.

10. Ananian P, Houvenaeghel G, Protiere C, Rouanet P, Arnaud S, Moatti JP, Tallet A, Braud AC, Julian-Reynier C: Determinants of patients' choice of reconstruction with mastectomy for primary breast cancer. Ann Surg Oncol 2004, 11:762-771.
11. Thompson TA, Pusic A, Kerrigan CL, Sargeant R, Slezak S, Chang BW, Helzlsouer KJ, Manson P: Surgeon perspectives on surgical options for early-stage breast cancer. Plast Reconstr Surg 2000, 105:910-918.

12. Baxter NN, Virnig BA, Durham SB, Tuttle TM: Trends in the treatment of ductal carcinoma in situ of the breast. J Natl Cancer Inst 2004, 96:443-448.

13. Kronowitz SJ, Robb GL: Breast reconstruction with postmastectomy radiation therapy: current issues. Plast Reconstr Surg 2004, 114:950-960.

14. Brinton LA, Lubin JH, Burich MC, Colton T, Hoover RN: Mortality among augmentation mammoplasty patients. Epidemiology 2001, 12:321-326.

15. Koot VC, Peeters PH, Granath F, Grobbee DE, Nyren O: Total and cause specific mortality among Swedish women with cosmetic breast implants: prospective study. BMJ 2003, 326: 527-528.

16. Pukkala E, Kulmala I, Hovi SL, Hemminki E, Keskimaki I, Pakkanen M, Lipworth L, Boice JD Jr, McLaughlin JK: Causes of death among Finnish women with cosmetic breast implants, 19712001. Ann Plast Surg 2003, 51:339-342.

17. Pukkala E, Boice JD, Jr., Hovi SL, Hemminki E, Asko-Seljavaara S Keskimaki I, McLaughlin JK, Pakkanen M, Teppo L: Incidence of breast and other cancers among Finnish women with cosmetic breast implants, 1970-1999. J Long Term Eff Med Implants 2002, 12:271-279.

18. Beale S, Hambert G, Lisper HO, Ohlsen L, Palm B: Augmentation mammaplasty: the surgical and psychological effects of the operation and prediction of the result. Ann Plast Surg 1984, 13:279-297.

19. Ohlsen L, Ponten B, Hambert G: Augmentation mammaplasty: a surgical and psychiatric evaluation of the results. Ann Plast Surg 1979, 2:42-52.

20. Sihm F, Jagd M, Pers M: Psychological assessment before and after augmentation mammaplasty. Scand J Plast Reconstr Surg 1978, 12:295-298.

21. Gabriel SE, Woods JE, O'Fallon WM, Beard CM, Kurland LT, Melton LJ III: Complications leading to surgery after breast implantation. N Engl J Med 1997, 336:677-682.

22. Breiting VB, Holmich LR, Brandt B, Fryzek JP, Wolthers MS, Kjoller K, McLaughlin JK, Wiik A, Friis S: Long-term health status of Danish women with silicone breast implants. Plast Reconstr Surg 2004, 114:217-226. 